\title{
Characterizing, modeling, monitoring and remediating radionuclides in the subsurface: What is needed?
}

\author{
T. Nicholson, W. Reed, R. Cady and J. Noggle \\ U.S. Nuclear Regulatory Commission, 11545 Rockville Pike, Rockville, MD 20852, USA
}

\begin{abstract}
The U.S. Nuclear Regulatory Commission has the mission to protect people and the environment. To support this important mission, the U.S. NRC staff assesses techniques and methods to characterize, model, monitor, and remediate radionuclide releases and their migration through the subsurface. Insights from ongoing reviews of field investigations by NRC staff involving radionuclide transport in the subsurface illustrate the need to test and confirm conceptual site models (CSM). The assumptions and parameterization inherent to these CSMs which affect radionuclide release and transport should be tested. In particular, the unsaturated zone where many leaks and spills originate needs detailed characterization and confirmatory monitoring. A dose assessment to determine risk-informed compliance with regulatory criteria is used to evaluate the need for and selection of remediation methods. If remediation is warranted, the choice of remediation method(s) is based upon site- and source-characterization, modeling and monitoring data. These data should be used to the test the CSM. Remediation options range from highly-aggressive methods such as pump, treat, monitor, and recycle or release; to more passive methods such as monitored natural attenuation. All successful remediation strategies involve monitoring programs to determine their efficacy. This monitoring is coupled to performance assessment models using performance indicators (PIs). These PIs provide a measurable indication of remediation performance and are derived from analysis of the CSM and monitoring data.
\end{abstract}

\section{BACKGROUND}

The U.S. Nuclear Regulatory Commission (U.S. NRC) has the mission to protect people and the environment. To support this important mission, the U.S. NRC staff assesses techniques and methods to characterize, model, monitor, and remediate radionuclide releases and their migration through the subsurface.

A series of uncontrolled releases of radionuclides (principally tritium) to the subsurface at commercial nuclear power plants (NPP) has occurred over the past decade. These releases originated from nuclear plant structures, systems, and components that store or convey liquids and gases containing radionuclides; leaks from spent fuel pools, vacuum breakers, pipes within concrete pipe vaults, buried pipes, and condensate storage tanks. Although the radionuclides released from these underground leaks primarily consisted of tritium, the contamination often included a variety of radionuclides unique to each plant (in one case, strontium-90, nickel-63, and cesium-137) (see Table 1 for ranked list of radionuclides [1].).

\section{RESPONSES}

As a result of these releases to the subsurface, the U.S. NRC convened a "Ground-Water Contaminant Task Force" (GWTF) to review information and insights from U.S. NRC staff investigations of leaks and spills at nuclear power plants [2]. The GWTF report included observations and recommendations on ground-water regulatory issues dealing with these leaks. Of particular interest was the information on how other international regulators are addressing similar issues [1]. Technical contacts resulting from these inquiries helped to establish close technical cooperation with the Canadian Nuclear Safety 
Table 1. Ranked list of radionuclides at commercial nuclear power plants (typical pressurized water reactor) based on their relative abundance, activity, and transport characteristics (after Scott, 2008).

\begin{tabular}{|c|c|c|}
\hline Relative Rank & Radionuclide & Half-Life* $^{*}$ (years) \\
\hline 1 & Strontium-90 & 28.90 \\
2 & Cesium-137 & 30.08 \\
3 & Cobalt-60 & 5.27 \\
4 & Hydrogen-3 & 12.32 \\
5 & Cesium-134 & 2.07 \\
6 & Iodine-129 & $1.57 \times 10^{7}$ \\
7 & Nickel-63 & 100.1 \\
8 & Carbon-14 & 5,700 \\
9 & Plutonium-238 & 87.7 \\
10 & Americium-241 & 432.6 \\
\hline
\end{tabular}

* From the National Nuclear Data Center, Brookhaven National Laboratory.

${ }^{\dagger}$ Hydrogen-3 is an alternative name for tritium.

Commission (CNSC). CNSC and NRC staffs have conducted three technical exchanges on tritium studies at nuclear facilities (both reactor and manufacturing licensees); ground-water protection related to uranium recovery facilities; and environmental risk assessments.

The Electric Power Research Institute conducted research on ground-water monitoring and remediation and has shared research reports with the NRC staff on "Ground-Water Monitoring Guidance for Nuclear Power Plants," [3] and "Ground-Water Protection Guidelines for Nuclear Power Plants" [4]. In 2007, following underground leaks at a number of nuclear sites, the Nuclear Energy Institute established a voluntary "Ground-Water Protection Initiative" (NEI 07-07) for all nuclear power plants [5]. NEI 07-07 defines a significant release as one exceeding 100 gallons from a source containing licensed materials that is greater than the radiological effluent technical specification (RETS) lower-level of detection (LLD) [5]. The goal of this initiative was to improve programs for preventing, detecting, and responding to inadvertent releases of low but detectable levels of plant-related materials in subsurface soil and water [5].

Recently, the American Nuclear Society and American National Standards Institute issued an industry-consensus standard ANSI/ANS-2.17-2010 "Evaluation of Radionuclide Migration in the Subsurface at Commercial Nuclear Power Plants" [6]. This standard [6] incorporates valuable guidance on hydrogeologic characterization, conceptual site models (CSM), performance assessments, mathematical modeling, performance-confirmation monitoring, and information management. Its appendices provide listings of potentially relevant resources for conducting subsurface radionuclide transport characterization, monitoring, and modeling programs. Figure 1 provides a flowchart describing these various performance assessment activities and their interrelationship to demonstrate safety. ANSI 2.17's appendices [6] also include summaries of the information for defining, updating, and visualizing the conceptual site model (CSM); information and parameters required for characterizing site facility characterization; information and parameters for hydrogeologic characterization; hydrogeologic modeling; performance-confirmation monitoring; and information management.

\section{CONCEPTUAL SITE MODELS (CSM)}

Prior to 2007, it was difficult to identify the source of the release and understand the hydrology controlling migration of the contaminants to the accessible environment. These initial difficulties arose because many NPP sites had minimal or no on-site ground-water monitoring program prior to the Nuclear Energy Institute's ground-water protection initiative. One element of this initiative is a sitespecific conceptualization (CSM) of the hydrogeology and relevant plant activities and components. 


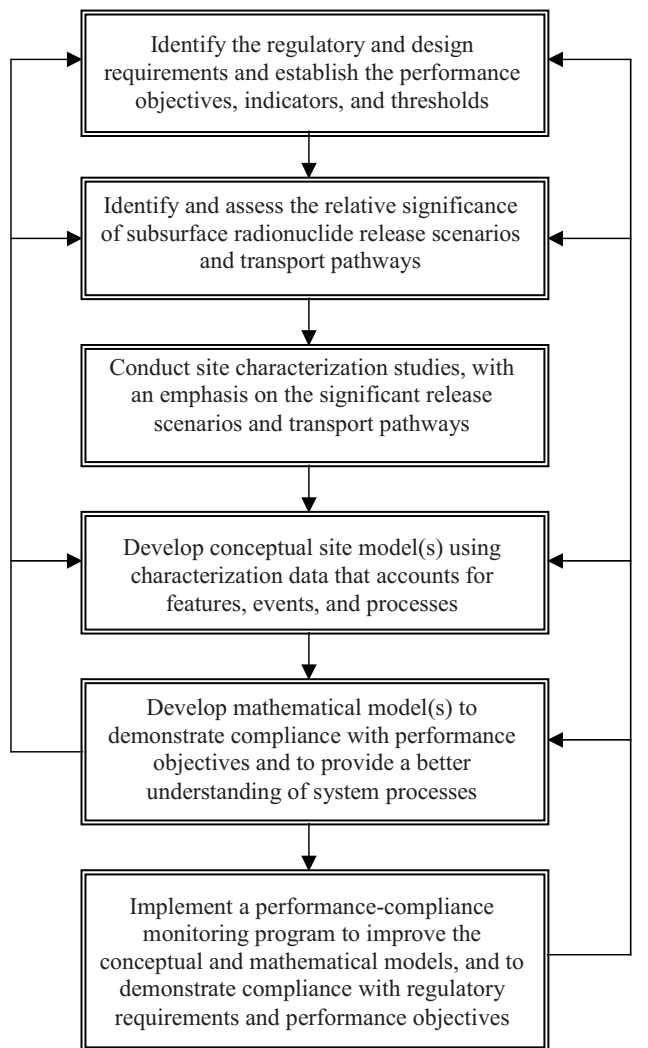

Figure 1. Flowchart describing performance assessment activities and the relationship among these activities (from ANSI/ANS-2.17-2010) [6].

The subsurface geometries of the structures, backfills, drains, sumps, ground-water extraction wells, buried cables and pipes, and other engineered systems affect radionuclide migration directions and rates. Leaks were often at or near the surface, above the local water table, requiring an understanding of flow and transport through partially-saturated soil or rock to the water table, or to nearby sumps or storm drains.

Insights from ongoing reviews of field investigations by U.S. NRC staff involving radionuclide transport in the subsurface illustrate the need to test and confirm conceptual site models (CSM). As shown in Figure 2, the first challenge is to identify and characterize the source term, and its migration path from the engineered system through engineered backfills to the water table [7].

The assumptions and parameterization inherent to these CSMs which affect radionuclide release and transport need to be tested. This testing may involve tracer tests, geophysical surveys, pumping tests and high-frequency monitoring to capture transient events such as deep percolation and groundwater recharge [8]. In particular, the unsaturated zone where many leaks and spills originate needs detailed characterization and confirmatory monitoring. U.S. NRC has ongoing research studies with the U.S. Department of Agriculture's Agricultural Research Service at the Beltsville Agricultural Research Center.

These studies involve monitoring and modeling ground-water flow and transport in the near surface. Recent work focused on model abstraction techniques to judge whether simplifications used in modeling introduce significant uncertainties and/or errors [8]. This research is analyzing multi-year, watershedscale tracer, ecological and hydrometeorological studies [8]. Approaches developed during these studies 


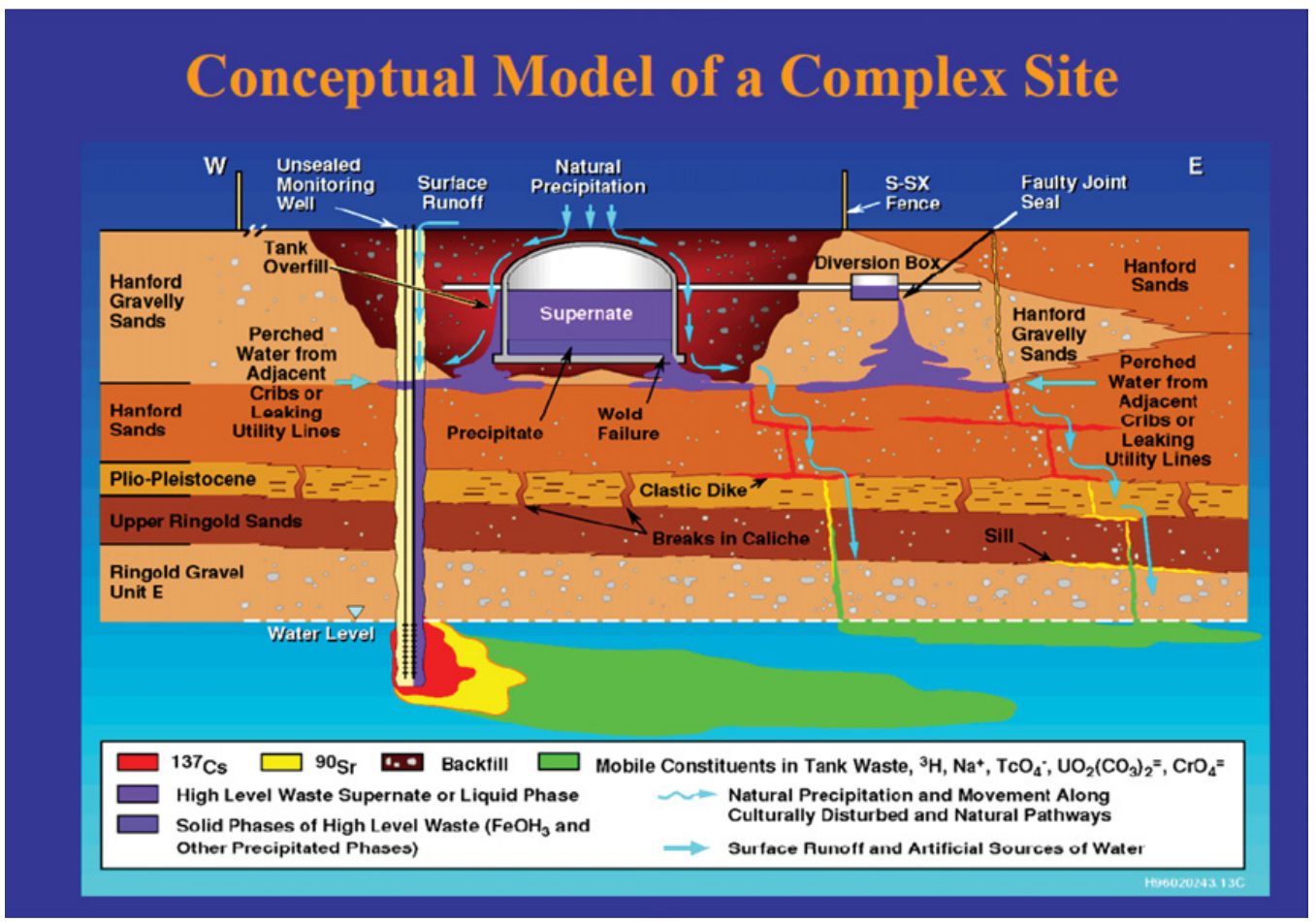

Figure 2. Conceptual models of complex sites include those hydrogeologic and engineered features that affect radionuclide release and migration to the ground water (from Ward et al., 1997) [7].

can be used to assess leak-generated infiltration, percolation, and migration to ground water that affect pathways.

\section{REMEDIATION}

U.S. NRC funded Brookhaven National Laboratory (BNL) to analyze its 13-year program of monitoring and modeling the tritium plume from the High Flux Beam Reactor and several strontium plumes from past operations at the Brookhaven Graphite Research Reactor. BNL documented it lessons learned from the integrated monitoring, modeling, and remediation program [9]. These lessons are being applied by $\mathrm{NRC}$ technical staff working on recent ground- water contamination at nuclear power plants. Figure 3 shows the basic steps in developing a remediation strategy [9].

Lessons learned in the BNL study [9] include: (1) a well developed process that ensure all elements are included in a risk-based remediation decision is needed; (2) facility monitoring is an important early line of defense in an environmental monitoring program; (3) it is important to understand the potential sources of contamination; (4) use of new techniques should be carefully planned and limitations fully understood before implementation; (5) initial efforts should focus on eliminating the source. Once the source is eliminated, a more accurate estimate of life-cycle remediation needs and associated costs can be determined; (6) release of contaminants from the vadose zone, particularly mobile contaminants such as tritium, needs to be considered as a continuing source term; (7) hot spot removal in ground water for mobile contaminants should be done as soon as possible since delays can lead to extensive and more complicated cleanup; (8) site ground-water model was essential tool used to (a) evaluate remedial alternatives; (b) select design criteria including appropriate downgradient extraction wells locations, 


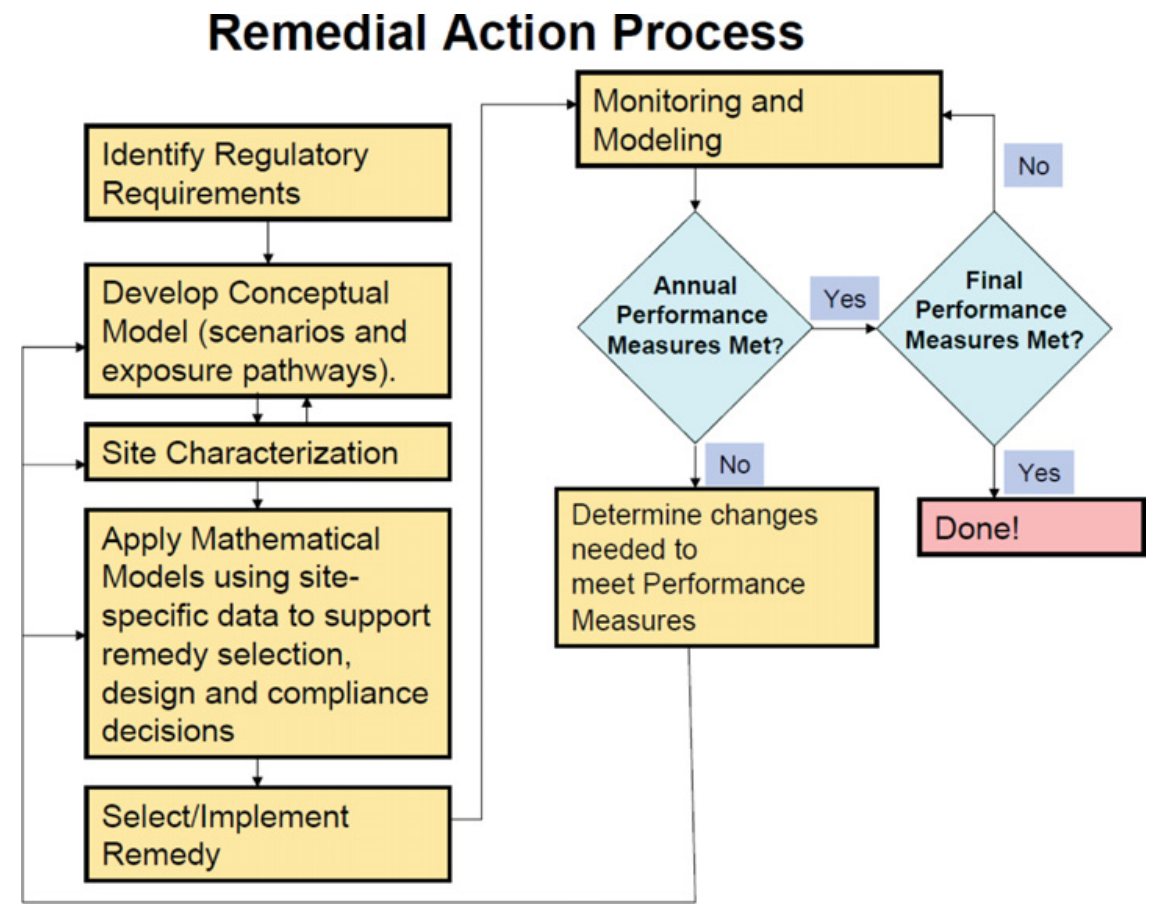

Figure 3. Basic steps in developing a remediation strategy that relates the Conceptual Site Model to Site Characterization, Monitoring and Modeling activities (from Sullivan and others, 2011) [9].

their pumping rates, well screen depths and capture zones; and (9) required cleanup work should be specified in a performance-based format with set goals.

A dose assessment to determine risk-informed compliance with regulatory criteria is a primary consideration for the NRC. In particular, the potential for a public drinking water pathway can increase the public dose and escalate the need for and selection of remediation methods. To determine whether ground-water remediation is needed and what remediation strategy should be pursued, one must analyze the ground-water monitoring data to define the contaminant plume and its behavior over time. At nuclear power plants, steps toward remediation have included identifying and stopping the leak, removing degraded fuel rods and debris from a spent fuel pool, pumping from an onsite pond to induce groundwater flow, transporting and recovering tritium, low-rate pumping from shallow wells followed by recycling through the nuclear plant system, and monitoring the natural attenuation of residual radioactive contamination in fractured rock.

If remediation is warranted, the choice of remediation method(s) is based upon site- and sourcecharacterization, modeling and monitoring data. These data should be used to test the CSM. Remediation options range from highly-aggressive methods such as pump, treat, monitor, and recycle or release; to more passive methods such as monitored natural attenuation. Remediation strategies range from relatively passive measures such as monitored natural attenuation to more active measures such as in situ bioremediation to pump, treat and release/recycle to excavate and removal [10]. The selection of the methods is a balance between reducing uncertainties and cost [10]. All successful remediation strategies involve monitoring programs to determine their efficacy [10]. This monitoring is coupled to performance assessment models using performance indicators (PIs). These PIs provide a measurable indication of remediation performance and are derived from analysis of the CSM and monitoring data [10]. 


\section{References}

[1] Scott, David, "Lessons Learned in Response to Ground-Water Contamination at NPPs and the EPRI Ground-Water Characterization Assistance Program," presented at the U.S. NRC Regulatory Information Conference, North Bethesda, Maryland, March 11 - 18, 2008.

[2] U.S. NRC, “Ground-Water Task Force Final Report," U.S. Nuclear Regulatory Commission, Rockville, MD, (June 2010).

[3] Electric Power Research Institute, "Ground-Water Monitoring Guidance for Nuclear Power Plants," EPRI Report 1011730, Palo Alto, CA, (September 2005).

[4] Electric Power Research Institute, "Ground-Water Protection Guidelines for Nuclear Power Plants,” EPRI Report 1015118 , Palo Alto, CA, (November 2007).

[5] Nuclear Energy Institute, "Industry Ground-Water Protection Initiative - Final Guidance Document," NEI 07-07, Washington, DC, (August 2007).

[6] American Nuclear Society, "American National Standard- Evaluation of Subsurface Radionuclide Transport at Commercial Nuclear Power Plants," ANSI/ANS-2.17-2010, ANS, La Grange Park, IL, 60526, Approved December 23, 2010 by the American National Standards Institute, Inc, (2011).

[7] Ward, A. et al., "A Comprehensive Analysis of Contaminant Transport in the Vadose Zone Beneath Tank SX-109," PNL-11463, Pacific Northwest National Laboratory, Richland, WA 99352, (1997).

[8] Pachepsky, Y. and others, "Application of Model Abstraction Techniques to Simulate Transport in Soils," NUREG/CR-7026, U.S. Nuclear Regulatory Commission, Washington, DC, March 2011.

[9] Sullivan, T. et al., "Lessons Learned in Detecting, Monitoring, Modeling and Remediating Radioactive Ground-Water Contamination," NUREG/CR-7029, U.S. NRC, Washington, DC, (April 2011).

[10] Long, P. et al., "Technical Basis for Assessing Uranium Bioremediation Performance," NUREG/CR-6973, U.S. Nuclear Regulatory Commission, Washington, DC, (April 2008). 